\section{Increased Survival of Rats irradiated with $X$-Rays and treated with Parathyroid Extract}

AN increase in the survival of rats irradiated with $\mathrm{X}$-rays has been found when parathyroid extract is given either before or after the irradiation.

In our experiments, each rat received 200 U.S.P. units $(2 \mathrm{ml}$.) of parathyroid extract (Eli Lilly) subcutaneously in the dorsothoracic region; control animals received an equal volume of normal saline. Both the parathyroid extract and the saline contained phenol as a preservative and were injected under sterile conditions. Males of a laboratory strain of hooded rats were used. They weighed $275-350 \mathrm{gm}$. at the beginning of each experiment. In one series, injections were given $12-18 \mathrm{hr}$. before irradiation. In a second series, animals were injected immediately after irradiation. All animals received $760 \mathrm{r}$. whole. body irradiation (measured in air) with $2,000 \mathrm{kVp}$. X-rays (1.5 m.amp.). This dose was given $65 \mathrm{~cm}$. from the target at $400 \mathrm{r}$. $/ \mathrm{min}$. No filters were used. Food and water were given ad libitum during the post-irradiation period.

When parathyroid extract was injected before or after irradiation, a difference was observed between the percentage surviving in the control and treated animals. By 20 days, this difference became highly significant (Table 1).

Table 1. EFFEOT OF PARATHYROID EXTRACT ON THE NUMBER OF RATS SURVIVING 760 R. WHOLE-BODY IRRADIATION WITH X-RAYS

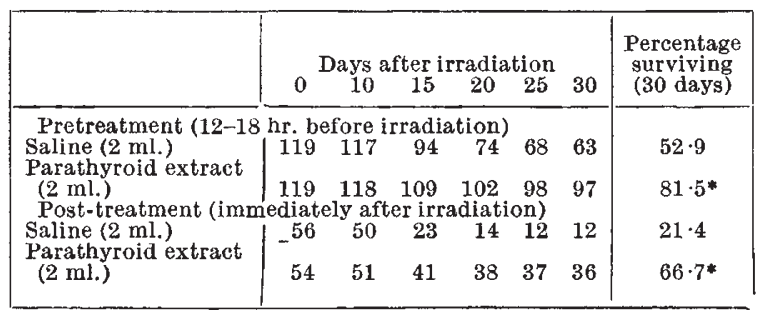

$* P<0.001$ (chi-square)

When parathyroid extract was injected before irradiation, survival at 30 days irradiation was 52.9 per cent in the controls and 81.5 per cent in the treated animals (Table 1). When injections were given after irradiation, survival was $21 \cdot 4$ per cent in the controls and $66 \cdot 7$ per cent in the treated rats. This represents an increase in survival of $28 \cdot 6$ per cent and $45 \cdot 3$ per cent for rats injected with para. thyroid extract before and after irradiation, respectively. These differences were highly significant $(P<0.001)$.

Between 30 and 60 days, the difference between the percentage surviving in the controls and treated animals was still evident, although slightly reduced. The percentage surviving in the controls was $51 \cdot 3$ and in the treated rats was $73 \cdot 1$, when treatment was administered before the irradiation. In rats injected after irradiation, the corresponding percentages at 60 days were $16 \cdot 1$ and $57 \cdot 4$.

It is not clear why fewer animals survived in the control group injected with saline immediately after irradiation (21.4 per cent) than in the controls injected before irradiation (52.9 per cent) (Table 1). However, a much greater proportion of gastrointestinal hæmorrhage occurred in the animals which died in the series injected after irradiation. This may have been the cause of the difference.
We conclude that the parathyroid extract used protects against radiation death. Experiments are in progress to determine whether this effect is a result of the activity of the hormone (that is, its ability to increase serum calcium ${ }^{1}$ ) or to some other property of the extract.

\section{R. H. RIXoN \\ J. F. WHITFIELD \\ T. Youdale}

Biology Branch,

Atomic Energy of Canada, Limited, Chalk River, Ontario.

${ }^{1}$ Collip, J. B., J. Biol. Chem., 63, 395 (1925).

\section{Protective Action of Venoms containing Phosphatidase-A against Certain Bacterial Exotoxins}

WE reported recently that a fraction of venom of the Australian tiger snake (Notechis scutatus scutatus), rich in hæmolysin, protects mice against both the dermonecrotic and lethal action of staphylococcal alpha toxin. Such an effect is observed when this fraction of the venom is injected either together with the toxin or separately ${ }^{1}$.

Further work has shown that protection is not afforded by the crude venom of the tiger snake, nor by a fraction of the venom rich in neurotoxin but poor in hrmolysin. On the other hand, we have observed that the crude venom of the Australian black snake (Pseudechis porphyriacus), of the king brown snake (Pseudechis australis), and of the honey bee (Apis mellifera) gives the same order of protection against the lethal action of staphylococcal toxin in mice as does the hæmolysin-rich fraction of the venom of the tiger snake. The former three venoms, like that of the tiger snake, are strongly hæmolytic, all containing the enzyme phosphatidase-A (Boery, H. M. D., unpublished work). Unlike the venom of the tiger snake, however, they are not powerfully neurotoxic.

By toxoiding the hrmolysin-rich fraction of the venom of the tiger snake with 0.2 per cent formalin, the ratio of the resultant toxicity to the protective power was reduced from that of the untoxoided material. A notable protection against the lethal action of staphylococcal toxin was obtained with this toxoided fraction when it was administered up to $30 \mathrm{~min}$. after the staphylococcal toxin.

Further, we have observed that both this toxoided fraction of tiger-snake venom and non-toxoided crude bee venom protect mice against intraperitoneal challenge with living staphylococci, the virulence of which was enhanced by Boake's ${ }^{2}$ method (Table 1). This finding supports evidence that death following the intraperitoneal injection of mice with such living challenge is due to the production of alpha toxin (North, E. A., unpublished work).

It is known that the products of the action of phosphatidase- $A$ on lecithin are a fatty acid and lysolecithin. Further, it was shown many years ago that soaps of certain long-chain fatty acids neutralize a number of bacterial toxins in vitro ${ }^{3}$.

We have confirmed these findings as regards staphylococcal alpha toxin, tetanus toxin and diphtheria toxin using either sodium oleate or sodium linoleate. We have failed to demonstrate protection with the soap of the corresponding saturated acid, sodium stearate. In addition, we have observed that 